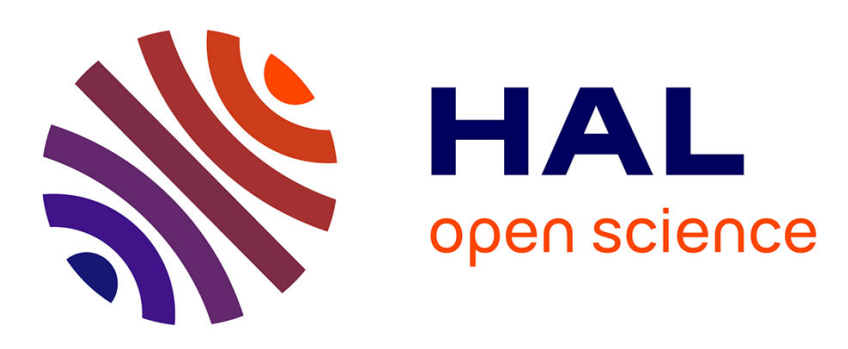

\title{
Wet snow backscattering sensitivity on density change for SWE estimation
}

Nikola Besic, Gabriel Vasile, Jocelyn Chanussot, Srdjan Stankovic, Didier Boldo, Guy d'Urso

\section{To cite this version:}

Nikola Besic, Gabriel Vasile, Jocelyn Chanussot, Srdjan Stankovic, Didier Boldo, et al.. Wet snow backscattering sensitivity on density change for SWE estimation. IGARSS 2013 - IEEE International Geoscience and Remote Sensing Symposium, Jul 2013, Melbourne, Australia. pp.1174-1177. hal00852099

\section{HAL Id: hal-00852099 \\ https://hal.science/hal-00852099}

Submitted on 20 Aug 2013

HAL is a multi-disciplinary open access archive for the deposit and dissemination of scientific research documents, whether they are published or not. The documents may come from teaching and research institutions in France or abroad, or from public or private research centers.
L'archive ouverte pluridisciplinaire HAL, est destinée au dépôt et à la diffusion de documents scientifiques de niveau recherche, publiés ou non, émanant des établissements d'enseignement et de recherche français ou étrangers, des laboratoires publics ou privés. 


\title{
WET SNOW BACKSCATTERING SENSITIVITY ON DENSITY CHANGE FOR SWE ESTIMATION
}

\author{
N. Besic ${ }^{1,2}$, G. Vasile ${ }^{1}$, J. Chanussot ${ }^{1,3}$, S. Stankovic ${ }^{2}$, D. Boldo ${ }^{4}$ and G. d'Urso ${ }^{4}$ \\ ${ }^{1}$ GIPSA-Lab, CNRS/Grenoble Institute of Technology, Grenoble, France \\ ${ }^{2}$ Faculty of Electrical Engineering, University of Montenegro, Podgorica, Montenegro \\ ${ }^{3}$ Faculty of Electrical and Computer Engineering, University of Iceland, Reykjavik, Iceland \\ ${ }^{4}$ R\&D STEP, Electricity of France (EDF), Chatou, France
}

\begin{abstract}
This paper deals particularly with the sensitivity of the wet snow backscattering coefficient on density change. The presented backscattering model is based on the approach used in the dry snow analysis [1], appropriately modified to account for the increased dielectric contrast caused by liquid water presence. It encircles our undertaking of simulating and analysing snow backscattering using fundamental scattering theories (IEM-B, QCA, QCA-CP). The wet snow parameters are chosen according to the area of the particular interest - the French Alps, while the choice of the SAR sensor parameters (frequency, polarization) is primarily conditioned by the initially settled goal - reaching qualitative conclusions concerning wet snow backscattering mechanism. Based on simulation results, we state the dominance of the snow pack surface backscattering component, causing the backscattering to be directly proportional to the volumetric liquid water content. This result is confirmed by the performed in situ measurements. We illustrate as well the decrease of this effect with the increase in operating frequency.
\end{abstract} SAR

Index Terms - backscattering, wet snow, density, SWE,

\section{INTRODUCTION}

Considering the significance of snow cover as a water resource in mountainous regions, the estimation of snow water equivalent (SWE), the parameter providing the amount of liquid water contained in the snow pack, represents a matter of particular interest. This parameter is a function of two independent snow physical properties: density and depth [2]. Due to the numerous difficulties in performing "in situ" measurements of those properties (high altitudes, global coverage), the SWE estimation occurs to be suitable for SAR remote sensing [3]. The imposing issue is the fact that the backscattering coefficient depends on many, both sensor and target,

Contact e-mail: nikola.besic@gipsa-lab.grenoble-inp.fr

This work was supported by the French National R\&DProgram TSEN-X PEPS UJF-CNRS 2011. parameters. Additionally, dielectric properties and therefore backscattering behaviour of a snow cover varies significantly upon its type. Namely, depending on the liquid water content, snow can be considered as dry or wet [4]. The former consists just of ice crystals embedded in air, while in the case of the later certain liquid water presence is assumed [5]. Consequently, relating as unambiguously as possible, snow density and depth to the SAR image pixel intensity remains an important and difficult challenge.

Our paper focuses on wet snow backscattering sensitivity on density change, or more concretely, on wetness (volumetric liquid water content) change. This parameter, defining wet snow density, affects considerably the value of SWE. It reflects the presence of water inclusions, which are responsible for wet snow dielectric and backscattering properties being notably different with respect to the dry snow ones $[4,6]$. The most profound investigation dealing with this problem, based on two phase backscattering model [7], suggested mostly negative relationship between backscattering coefficient and the wetness (for values of wetness $<4.5 \%$ ). The positive relationship was noticed just in case of lower operating frequency (L band). Strong influence of the shape of water inclusions was reported, also.

The conclusions we reached are quantitatively different. The wet snow backscattering simulations, presented in this paper, indicate the dominance of the snow pack surface backscattering component. This leads to the positive relationship between the wetness and the backscattering coefficient at all three analysed bands (L, C and X). Those results are confirmed by in situ measurements at $\mathrm{X}$ band. The presented snow backscattering simulator is based on the classical single layer snow backscattering model [8]. The surface backscattering and wet snow volume behaviour are simulated using respectively Integral Equation Model (IEM-B) [8] and Dense Media Radiative Transfer (DMRT) with Quasi Crystalline Approximation with Coherent Potentials (QCA-CP) [9].

Presented conclusions, along with the ones given in [1], are used in the development of the wet snow mapping method [10] as well as in building the ground for semi-empirical mod- 


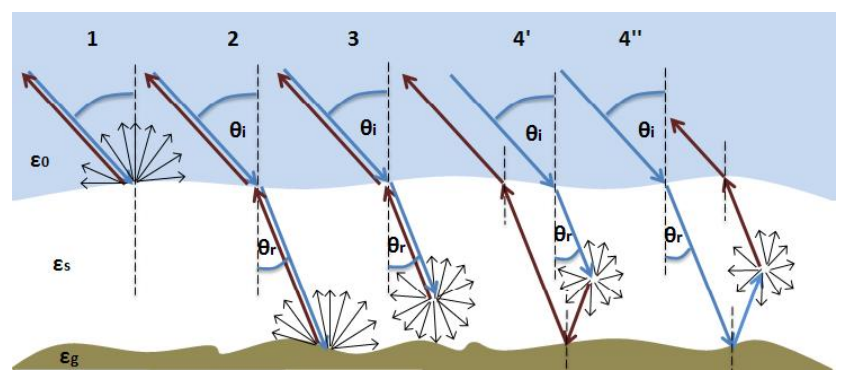

Fig. 1. Snow pack backscattering mechanism.

els providing an unambiguous link between backscattering coefficient and snow density.

\section{BACKSCATTERING SIMULATOR}

Given that the paper represents a sequel to [1], in this section we introduce the general frame and the particularities of wet snow backscattering simulator with respect to the presented dry snow one.

Wet snow dielectric constant is a complex quantity, function of the corresponding dry snow density (hence, of the ice volume fraction $f_{i}$ ), wetness (volumetric liquid water content) $w$ and frequency $f$. For the frequency range of $3 \mathrm{GHz}$ - $15 \mathrm{GHz}$, it is approximated as [6,5]:

$$
\begin{aligned}
\varepsilon_{w s} & =1+1.83 \cdot 0.917 f_{i}+0.02 w^{1.105}+ \\
& +\frac{0.073 w^{1.31}}{1+\left(\frac{f}{9.07}\right)^{2}}+j \frac{0.073 \frac{f}{9.07} w^{1.31}}{1+\left(\frac{f}{9.07}\right)^{2}}
\end{aligned}
$$

Unlike the dry snow one, wet snow dielectric constant, being a complex quantity, has its imaginary part, indicating the presence of the medium absorption losses.

Total backscattering of the wet snow pack is as well decomposed as the sum of the four components $[8,1]$ (fig. 1):

1. Snow pack surface component,

2. Underlying ground surface component,

3. Snow volume component,

4. Ground-volume interaction component.

Integral Equation Model (IEM-B) is used for simulating surface backscattering [8], with the assumption of the isotropic exponential correlated surface, introduced through the surface spectra.

Unlike dry snow, wet snow medium is characteristic for its big spatial variation of dielectric permittivity [9]. That sort of large difference between host and particle dielectric constant requires applying a modified QCA theory where coherent wave "sees" new average medium rather than the host one - QCA with Coherent Potentials (QCA-CP). The extinction coefficient $\left(\kappa_{e}\right)$ is computed using effective permittivity $\left(\varepsilon^{e f f}\right)$ as:

$$
\begin{aligned}
\kappa_{e} & =2 k \Im\left\{\sqrt{\varepsilon^{e f f^{\prime}}+j \varepsilon^{e f f^{\prime \prime}}}\right\} \\
\varepsilon^{e f f^{\prime}} & =1+\frac{3 f_{p}\left(\varepsilon_{p}-1\right) \varepsilon^{e f f 0}}{3 \varepsilon^{e f f 0}+\left(1-f_{p}\right)\left(\varepsilon_{p}-1\right)} \\
\varepsilon^{e f f^{\prime \prime}} & =\frac{2\left(k r_{p} \sqrt{\varepsilon^{e f f 0}}\right)^{3} 3 f_{p}\left(\varepsilon_{p}-1\right)^{2}\left(1-f_{p}\right)^{4} \varepsilon^{e f f 0}}{\left[3 \varepsilon^{e f f 0}+(1-f p)\left(\varepsilon_{p}-1\right)\right]^{2}\left(1+f_{p}\right)^{2}}
\end{aligned}
$$

with $\varepsilon^{e f f 0}$ being the effective permittivity when multiple scattering effects are neglected and $k$ the wavenumber. The water inclusions are introduced through the mixed ice-water spherical particles occupying volume fraction $f_{p}$ [11], with $r_{p}$ and $\varepsilon_{p}$ being respectively their effective radius and dielectric constant:

$$
\begin{aligned}
r_{p} & =r_{i}\left(\frac{f_{p}}{f_{i}}\right)^{\frac{1}{3}} \\
\frac{\varepsilon_{p}-1}{\varepsilon_{p}+1} & =\frac{\left(\varepsilon_{l w}-1\right)\left(\varepsilon_{i}+2 \varepsilon_{l w}\right)+\left(\frac{r_{i}}{r_{p}}\right)^{3}\left(\varepsilon_{i}-\varepsilon_{l w}\right)\left(1+2 \varepsilon_{l w}\right)}{\left(\varepsilon_{l w}+2\right)\left(\varepsilon_{i}+2 \varepsilon_{l w}\right)+2\left(\frac{r_{i}}{r_{p}}\right)^{3}\left(\varepsilon_{i}-\varepsilon_{l w}\right)\left(\varepsilon_{l w}-1\right)}
\end{aligned}
$$

The wet snow electromagnetic absorption is not negligible and therefore it is necessary to introduce the albedo coefficient as the ratio of the scattering $\left(\kappa_{s}\right)$ and the extinction coefficient [11]:

$$
a=\frac{\kappa_{s}}{\kappa_{e}}=\frac{2 r_{p}^{3} f_{p}\left|\frac{k^{2}\left(\varepsilon_{p}-1\right) \varepsilon^{e f f 0}}{3 \varepsilon^{e f f 0}+(1-f p)\left(\varepsilon_{p}-1\right)}\right|^{2} \frac{\left(1-f_{p}\right)^{4}}{\left(1+f_{p}\right)^{2}}}{\kappa_{e}}
$$

The selected values of input parameters are set either according to [5], [12] (for the ice and water dielectric permittivities), or according to the local in situ measurements in the region of the French Alps (Electricité de France, Météo-France.). The surface Root Mean Square (RMS) height represents a potential exception given that the value of this parameter is strictly imposed by the IEM-B model limitations and by the constrain of using same surface properties for each frequency band (limitting value at $10 \mathrm{GHz}$ ) [8].

\begin{tabular}{||l|c||}
\hline Input parameter & Wet snow \\
\hline Snow density & $220,240,260,280,300 \mathrm{~kg} / \mathrm{m}^{3}$ \\
\hline Wetness $(w)$ & $3.6,5.6,7.6,9.6,11.6 \%$ \\
\hline Snow depth & $2 \mathrm{~m}$ \\
\hline Frequency $(f)$ & $1.5(\mathrm{~L}), 6(\mathrm{C}), 10(\mathrm{X}) \mathrm{GHz}$ \\
\hline Ice particle effective radius $\left(r_{i}\right)$ & $225(121,169,225,289,361) \mu \mathrm{m}$ \\
\hline Ice dielectric constant $\left(\varepsilon_{i}\right)$ & 3.15 \\
\hline Water dielectric constant $\left(\varepsilon_{l w}\right)$ & $80+j 50$ \\
\hline Snow RMS height & $(9,10,11) \mathrm{mm}$ \\
\hline Snow correlation length & $50 \mathrm{~mm}$ \\
\hline Ground dielectric constant & $(5,5.5,6,6.5,7)$ \\
\hline Ground RMS height & $(11,12,13) \mathrm{mm}$ \\
\hline Ground correlation length & $50 \mathrm{~mm}$ \\
\hline
\end{tabular}

Table 1. Input parameters for the wet snow backscattering simulations (the results are averaged over the values in the brackets). 


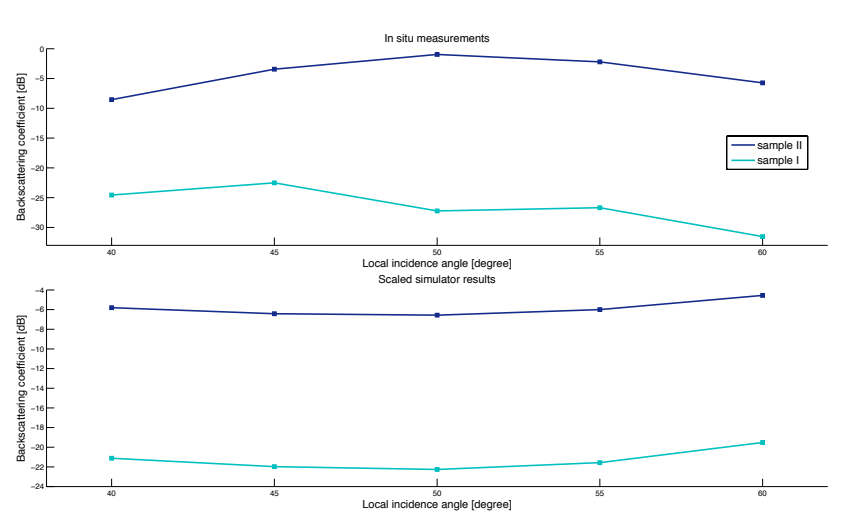

Fig. 2. "In situ" measurements

\section{IN SITU MEASUREMENTS}

This section briefly describes the analysis of $\mathrm{X}$-band ground based radar measurements (VV polarization channel) acquired on the 23rd of April 2013, in the Grand Rousse region of the French Alpes. Two sets of measurements were performed over the same spot (same surface parameters) at 4 hour interval. The first set of range profiles was acquired in the morning, while the second acquisition took place in the afternoon, allowing snow wetness variation in the upper snow layer due to the sunny weather conditions. The parameters of the upper snow layer which characterize the snow pack surface backscattering component were carefully measured (see Table 2).

\begin{tabular}{||l|c|c||}
\hline Parameter & Sample I & Sample II \\
\hline Acquisition time & $11 \mathrm{~h} 00$ & $15 \mathrm{~h} 00$ \\
\hline Snow dielectric constant & 2.94 & 4.39 \\
\hline Wetness $(w)$ & $06.8 \%$ & $16.00 \%$ \\
\hline Snow density & $175 \mathrm{~kg} / \mathrm{m}^{3}$ & $250 \mathrm{~kg} / \mathrm{m}^{3}$ \\
\hline Snow depth & $2.15 \mathrm{~m}$ & $2.15 \mathrm{~m}$ \\
\hline
\end{tabular}

Table 2. In situ measurements: snow parameters.

The backscattering coefficients for different local incidence angles are derived from the corresponding ground range profiles. Fig. 2 illustrates the comparison between the measured and the scaled simulated backscattering sensitivity on upper layer wetness.

\section{RESULTS AND CONCLUSIONS}

The absolutely dominant component in case of a wet snow backscattering is the snow pack surface component (first component in Fig. 1). In Fig. 3, it can be seen that its share in total backscattering, after the rise at the lower frequencies, decrease with the increase in frequency. This appears to be similar to the role of the underlying ground component in case of a dry snow backscattering [1].

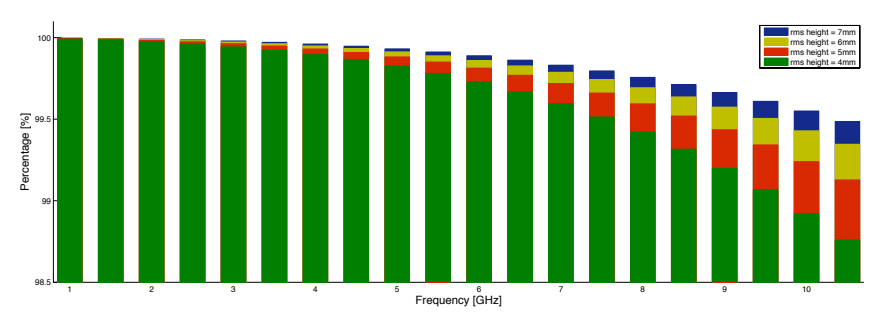

Fig. 3. Snow pack surface component proportion in total backscattering as a function of the operating frequency.

The observed significant sensitivity of wet snow backscattering to density change (Fig. 5), or more concretely to the wetness change, is exactly the consequence of the snow pack surface component dominance. The increased wetness means increased wet snow dielectric constant (Fig. 4), leading to the more intensive snow surface backscattering at the particular frequency [8].

The same effect ought to be achieved with the increase of frequency but, on the other side, this increase is causing as well the decrease of wet snow dielectric constant (Fig. 4). The backscattering decrease due to the later effect exceeds former increasing phenomena. This leads to the decrease in air-snow surface component share in total backscattering with the increase of frequency (Fig. 3).

The conducted in situ measurements confirmed the conclusions derived from the simulations. The backscattering appears to be more intense in case of an increased wetness of the upper snow layer (Fig. 2). This could be explained only by the dominance of the snow pack backscattering component.

Given that the shape of water inclusions doesn't influence the snow pack backscattering component, its influence is not been analysed in this paper. However, the modelling of water inclusions through the mixed ice-water spherical particles could be treated as the principal drawback of the presented simulator with respect to the state of art [7].

Given the present issue with wet snow depth and underlying layers density estimation, the behaviour illustrated in Fig. 3 can be taken as potentially significant. This decrease of snow pack surface backscattering means increase of the

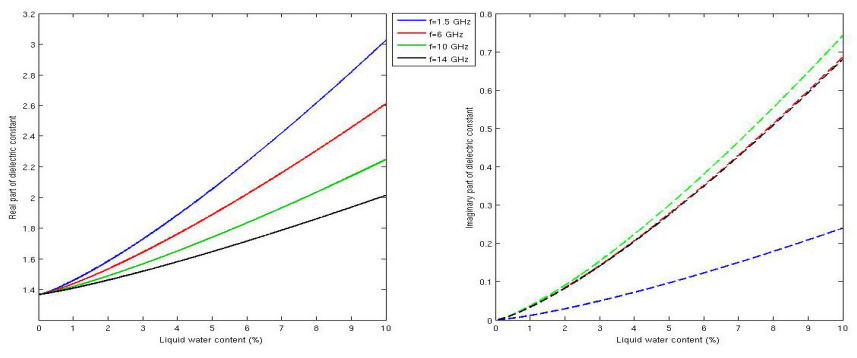

Fig. 4. Wet snow dielectric constant as a function of the liquid water content and the operating frequency. 


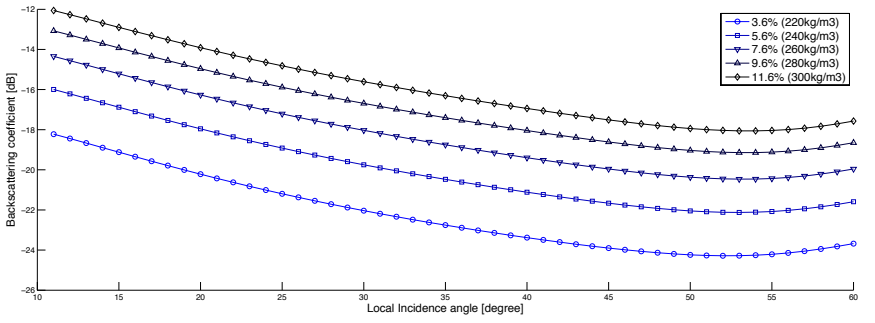

(a)

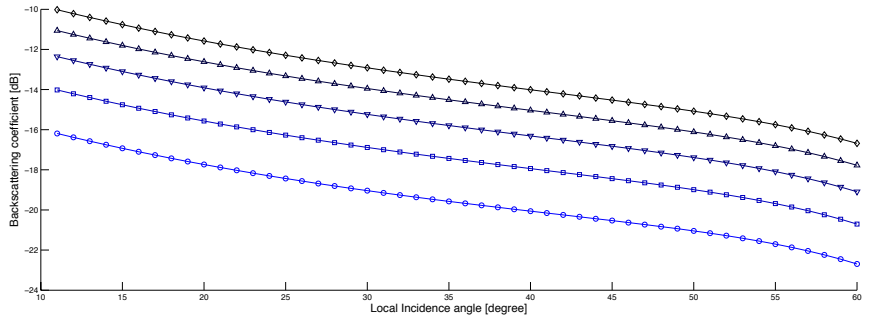

(b)

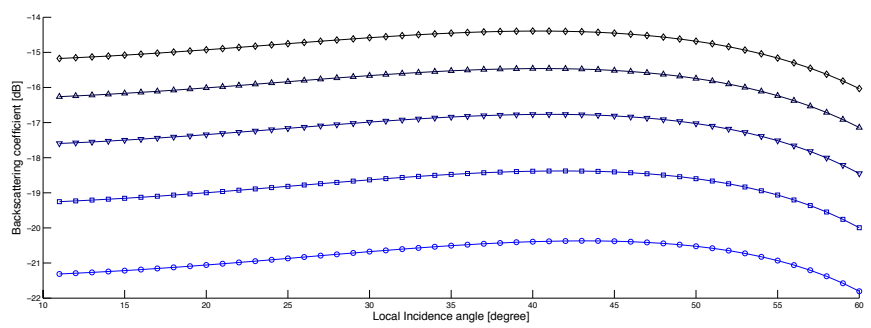

(c)

Fig. 5. Wet snow backscattering on density change, VV polarization: (a) L band, (b) C band, (c) X band.

other components proportion, volume and ground-volume interaction in the first line, which could provide us with some useful information about the snow volume. It implies that, unlike for the dry snow, where lower frequency bands proved to be pretty useful in density and depth estimation [2], the extraction of wet snow parameters ought to be performed in the higher frequency bands.

\section{REFERENCES}

[1] N. Besic, G. Vasile, J. Chanussot, S. Stankovic, J. P. Ovarlez, G. d'Urso, D. Boldo, and J. P. Dedieu, "Dry snow backscattering sensitivity on density change for swe estimation," in Proc. IEEE International Geoscience and Remote Sensing Symposium (IGARSS'12), Munich, Germany, 2012, pp. 4418-4421.

[2] J. Shi and J. Dozier, "Estimation of snow water equivalence using sir-c/x-sar, part i: Inferring snow density and subsurface properties," IEEE Trans. Geosci. Remote Sens., vol. 38, no. 6, pp. 2465-2474, 2000.

[3] H. Rott and C. Matzler, "Possibilities and limits of synthetic aperture radar for snow and glacier surveying," Annals of Glaciology, , no. 9, pp. 195-199, 1987.

[4] T. Nagler and H. Rott, "Retrieval of wet snow by means of multitemporal sar data," IEEE Trans. Geosci. Remote Sens., vol. 38, no. 2, pp. 754-765, 2000.

[5] W. G. Rees, Remote Sensing of Snow and Ice, CRC Press, Taylor and Francis Group, Boca Raton, FL, USA, 2006.
[6] M. T. Hallikainen and D. P. Winebrenner, Microwave Remote Sensing of Sea Ice, chapter The physical basis for sea ice remote sensing, American Geophysical Union, 1992.

[7] A. N. Arslan, M. T. Hallikainen, and J. T. Pulliainen, "Investigating of snow wetness parameter using a twophase backscattering model," IEEE Trans. Geosci. Remote Sens., vol. 43, no. 8, pp. 1827-1833, 2005.

[8] A. K. Fung, D. Schutzer, and K. S. Chen, Microwave Scattering and Emission Models for Users, Artech House, Norwood, MA, USA, 2010.

[9] L. Tsang, J.A. Kong, K.H. Ding, and C.O. Ao, Scattering of Electromagnetic Waves, Vol. 2: Numerical Simulations, Wiley Interscience, 2001.

[10] N. Besic, G. Vasile, J. Chanussot, S. Stankovic, J. P. Ovarlez, G. d'Urso, D. Boldo, and J. P. Dedieu, "Stochastically based wet snow mapping with sar data," in Proc. IEEE International Geoscience and Remote Sensing Symposium (IGARSS'12), Munich, Germany, 2012, pp. 4859-4862.

[11] Nicolas Longepe, Snow Remote Sensing using Spaceborne SAR Imagery at L-and C-Bands, Ph.D. thesis, University of Rennes I, Rennes, FR, 2008.

[12] Jonathan H. Jiang and Dong L. Wu, "Ice and water permittivities for millimeter and sub-millimeter remote sensing applications," Atmospheric Science Letters, , no. 5, pp. 146-151, 2004. 